\title{
Anadromy and the dispersal of an invasive fish species (Oncorhynchus mykiss) in Eastern Quebec, as revealed by otolith microchemistry
}

Thibault I, Hedger RD, Dodson JJ, Shiao J-C, lizuka Y, Tzeng W-N. Anadromy and the dispersal of an invasive fish species (Oncorhynchus mykiss) in Eastern Quebec, as revealed by otolith microchemistry. Ecology of Freshwater Fish 2010. (C) 2010 John Wiley \& Sons A/S

Abstract - Rainbow trout (Oncorhynchus mykiss) is invading rivers bordering the St. Lawrence Estuary (Quebec, Canada). Some rivers in Eastern Quebec support self-sustaining populations while adult vagrants are frequently captured in rivers where no reproduction has been confirmed. We hypothesised that the development of anadromy has promoted the species dispersal. Otolith $\mathrm{Sr}: \mathrm{Ca}$ analyses revealed that although all fish captured in the upstream stocking region were freshwater residents, both anadromous and freshwater resident phenotypes were found downstream in Eastern Quebec. The proportion of fish exhibiting the anadromous life cycle increased with the distance from the stocking zone. Eastern Quebec steelhead migrated to sea at the same age but at a larger size than steelhead within their native range. Age at first reproduction was similar to that observed in native populations. The development of the anadromous life cycle enables this species to colonise new rivers following long-distance migrations along the St. Lawrence Estuary corridor.

\author{
I. Thibault', R. D. Hedger ${ }^{2}$ \\ J. J. Dodson', J.-C. Shiao ${ }^{3}$, \\ Y. lizuka ${ }^{4}$, W.-N. Tzeng ${ }^{5}$
}

${ }^{1}$ Département de biologie, Québec-Océan, Université Laval, Québec, 1045 Avenue de la Médecine, Québec, Canada G1V 0A6, ${ }^{2}$ Norwegian Institute for Nature Research, N0-7485 Trondheim, Norway, ${ }^{3}$ nstitute of Oceanography, College of Science, National Taiwan University, Taipei, Taiwan 106, ROC, ${ }^{4}$ Institute of Earth Sciences, Academia Sinica, 128, Section 2, Academia Road, Nankang, Taipei, Taiwan 115, ROC, ${ }^{5}$ Institute of Fisheries Science, College of Life Science, National Taiwan University, Taipei, Taiwan 106, ROC

Key words: exotic fish invader; hierarchical filter; dispersion capacity; anadromy; freshwater residency; otolith microchemistry

Isabel Thibault, 1045 Avenue de la Médecine, Département de biologie, Québec-Océan, Université Laval, Québec, Québec, Canada G1V 0A6 Tel.: +1 418656 2131X7862, Fax: +1418656 2339; e-mail: isabel.thibault.2@ulaval.ca

Accepted for publication February 10, 2010

\section{Introduction}

Once established in a new habitat, the success of an exotic invader will depend on the species' capacity to disperse in that habitat and to increase its population size (Theoharides \& Dukes 2007). This is the last of the hierarchical filters which determine the success of biological invasions (Kolar \& Lodge 2001; Colautti et al. 2006; Moyle \& Marchetti 2006; Theoharides \& Dukes 2007). Characteristics associated with invaders capable of surpassing this last filter are numerous, including long-distance dispersal capacities, small body size, high fecundity, asexual reproduction, rapid growth and early maturity (Kolar \& Lodge 2001; Moyle \& Marchetti 2006; Theoharides \& Dukes 2007).

Rainbow trout (Oncorhynchus mykiss, Walbaum 1792) is one of the most widely introduced fish species in the world (GISD 2005). Stocking of this salmonid, originating from the Northern Pacific Ocean, has occurred throughout the world since 1874 with varying levels of success (MacCrimmon 1971; Burgner et al. 1992). Like several of its relatives of the Salmonidae family, rainbow trout may adopt two lifecycle forms: the anadromous phenotype, with a growth phase in saltwater, or the freshwater resident phenotype. Despite a prevailing tendency toward philopatry (Burgner et al. 1992), the anadromous phenotype may nevertheless migrate into new streams, hence increasing the species' capacity to disperse. Anadromy also implies larger size at reproduction for males and females. Larger body size is generally related to higher fitness, particularly among females who produce more and larger eggs with increasing body size (DuBois et al. 1989; Seamons et al. 2007 and references therein). However, the few naturally spawning populations of rainbow trout that have been established after an introduction event are usually 
composed of freshwater residents. The introduced selfsustaining population in the Santa Cruz River (Southern Patagonia) is the only one known to have developed an anadromous run (Pascual et al. 2001; Riva Rossi et al. 2004). The reason for the dominance of residency among introduced populations is not clear. It may be related to the phenotype of the introduced populations, which is usually resident. It may also be that the costs associated with anadromy in recently founded populations are higher than for residency, resulting in selection against migrants.

In Eastern Canada, stocking of rainbow trout has been conducted for several years in the upper St. Lawrence River system, from the Great Lakes to the vicinity of Quebec City, leading to the establishment of some self-sustaining populations in Eastern Quebec outside the area where stocking and farming of rainbow trout are permitted (Thibault et al. 2009). The first such population was discovered in the 1980s and reproduces in two rivers, Du Gouffre and Malbaie, located in the Charlevoix region, on the north shore of the St. Lawrence Estuary. In 2007-2008, young of the year $(0+)$ and other juveniles were also observed in two rivers (Matane and Les Mechins) located downstream, on the south shore of the St. Lawrence Estuary. Other than these established populations, adults have been frequently captured during many years in streams all along the estuary. Given that no reproduction has been detected in these rivers, captures are believed to be composed of vagrant fish. Genetic analyses revealed that such vagrants mainly originate from a population founded in Lake Ontario, and also from the recently established population in Charlevoix (Thibault et al. 2009). These findings suggest the presence of anadromous individuals in the population of the Malbaie and $\mathrm{Du}$ Gouffre rivers, which contradicts the belief that introduced self-sustaining populations of rainbow trout only support the freshwater resident form (Pascual et al. 2001; Riva Rossi et al. 2004).

The main objective of this study was to demonstrate that anadromy is involved in the colonisation process of Eastern Quebec by rainbow trout. We aimed to determine if the anadromous phenotype is present in recently naturalised populations in Eastern Quebec, which are believed to consist of mainly freshwater residents. We also tested the hypothesis that all vagrants should be anadromous. To determine the occurrence of anadromy, both direct (i.e., individual migratory behaviour) and indirect (maternal phenotype) observations were used. Our second objective was to characterise the anadromous phenotype in Eastern Quebec rivers. We thus determined the age and size at migration and at reproduction for steelhead (anadromous rainbow trout), and compared growth rates between the anadromous and resident phenotypes. Finally, we compared these characteristics with what is observed in populations found within their native range.

\section{Method}

\section{Sampling and measurements}

In 2005 and 2006, we obtained more than 200 rainbow trout from different sites in Quebec waters, including rivers, lakes, creeks and the St. Lawrence River and Estuary. Most rainbow trout (77\%) were provided by recreational fishers, whereas the remaining specimens came from commercial fisheries, the monitoring of dams and surveys performed by biologists and river managers. The majority of fish were captured from June to August. As fishing effort varied between sample locations, our sample did not reflect the real distribution and abundance of the species.

Fish were weighed, measured (fork length), and sexed. As biological information was mainly provided by fishers, some data were missing (especially mass) and their precision is somewhat uncertain. When possible, size and mass were measured again and sex was confirmed in the laboratory. A tissue sample was collected to determine if fish captured outside the stocking area originated from a domestic sterile strain used for stockings (triploid fish $-3 \mathrm{~N}$ ) or a wild population [refer to Thibault et al. (2009) for more details on the method]. Sagittal otoliths were extracted, cleaned with distilled water, dried in air and conserved in plastic Eppendorf tubes until otolith microchemistry analyses were performed (see section 'Otolith $\mathrm{Sr}: \mathrm{Ca}$ analysis and interpretation'). For the purpose of this study, only 140 specimens were kept for the otolith microchemistry analyses. Our selection criteria were: (i) the capture location, in order to represent different habitats, favouring fish captured to the east of Quebec City, (ii) the fish size, as larger individuals were believed to be older and therefore more likely to present a more complete life cycle, and (iii) the fish sex, to ensure a sample with an almost equal sex ratio. Ten farmed rainbow trout $(3+$ years of age) provided by a governmental hatchery (Lac-des-Écorces, LDE) were also analysed.

\section{Otolith Sr:Ca analysis and interpretation}

Samples preparation for electron probe micro-analysis of otoliths was performed in National Taiwan University. Quantitative chemical analyses of strontium ( $\mathrm{Sr}$ ) and calcium $(\mathrm{Ca})$ in otoliths were carried out by an electron probe micro analyser (EPMA: JEOL JXA8900R, JEOL, Akishima, Tokyo, Japan) and a wavelength dispersive spectrometer (WDS) at the Institute of Earth Sciences, Academia Sinica in Taipei. Secondaryand backscattered electron images were used to guide 
the analysis on target positions located along an axis from the core of the otolith to the edge at $10-\mu \mathrm{m}$ intervals. Beam conditions were $15 \mathrm{kV}$ for the acceleration voltage and $3 \mathrm{nA}$ for the current, and a $5 \times 4 \mu \mathrm{m}$ rectangular scanning beam was used. The $\operatorname{Sr} L \alpha$ peak position was measured for $80 \mathrm{~s}$ and each of the upper and lower baselines for $20 \mathrm{~s}$. The peak concentration of $\mathrm{Ca} K \alpha$ was measured for $20 \mathrm{~s}$ and each of the upper and lower baselines for $10 \mathrm{~s}$. The beam power density of $2.25 \mathrm{Wm}^{-2}$ was within the range of $0.5-3 \mathrm{Wm}^{-2}$ as suggested by Gunn et al. (1992), and the counting time was sufficient to ensure effective measurement.

The measured X-ray intensities were corrected by the PRZ [phi-rho-z, Reed (1993)] method using the standard calibration of natural and synthetic chemicalknown standard minerals; a strontianite $\left[(\mathrm{Sr} 0.95 \mathrm{Ca} 0.15) \mathrm{CO}_{3}\right.$ : NMNH-R10065 from National Museum of Natural History, Smithsonian Institution, Washington, DC, USA] for $\mathrm{Sr}$ and a synthesised aragonite $\left(\mathrm{CaCO}_{3}\right)$ for $\mathrm{Ca}$. Detection limits based on $3 \sigma$ of standard calibration were less than $400 \mathrm{ppm}$ for $\mathrm{Sr}$.

As the otolith $\mathrm{Sr}$ :Ca ratio increases with salinity (Zimmerman 2005), it is possible to distinguish periods when the fish grew in freshwater or the sea. Among the 150 otoliths selected for the analysis (140 captures +10 farmed specimens), some broke during the preparation or presented vaterite inclusions (Tzeng et al. 2007; Jessop et al. 2008), and so were discarded. Interpretation of the otolith Sr:Ca life-history transects was possible for 125 specimens, representing 29 different watercourses (and the LDE government hatchery, $N=8$ ), distributed over three sectors: (i) South-western Quebec (SWQ), including six stocked creeks and lakes in the upper part of the St. Lawrence River, (ii) Quebec City (QC), comprising ten rivers located within $70 \mathrm{~km}$ of Quebec City, at the downstream limit of the stocking area, and (iii) Eastern Quebec (EQ), consisting of 13 rivers located outside the stocking area (Fig. 1). Following analysis, one specimen was discarded (see below).

Among fish captured inside the stocking area, 41 were a priori known to be freshwater residents. Twenty-one were farmed fish that either came directly from the LDE government hatchery $(N=8)$ or were captured in lakes shortly after stocking events (SWQ, $N=13)$. Another 20 specimens were caught upstream of two impassable waterfalls $(\mathrm{QC}, N=13)$ or came from watercourses located far away from the nearest marine habitat (SWQ, $N=7$ ) (Fig. 1). All these fish were used to establish the threshold demarcating fresh from marine (or brackish) water habitats (thereafter called FW-threshold). Their mean otolith $\mathrm{Sr}: \mathrm{Ca}$ values varied from 0.327 to $3.684 \times 10^{-3}$, with an average of

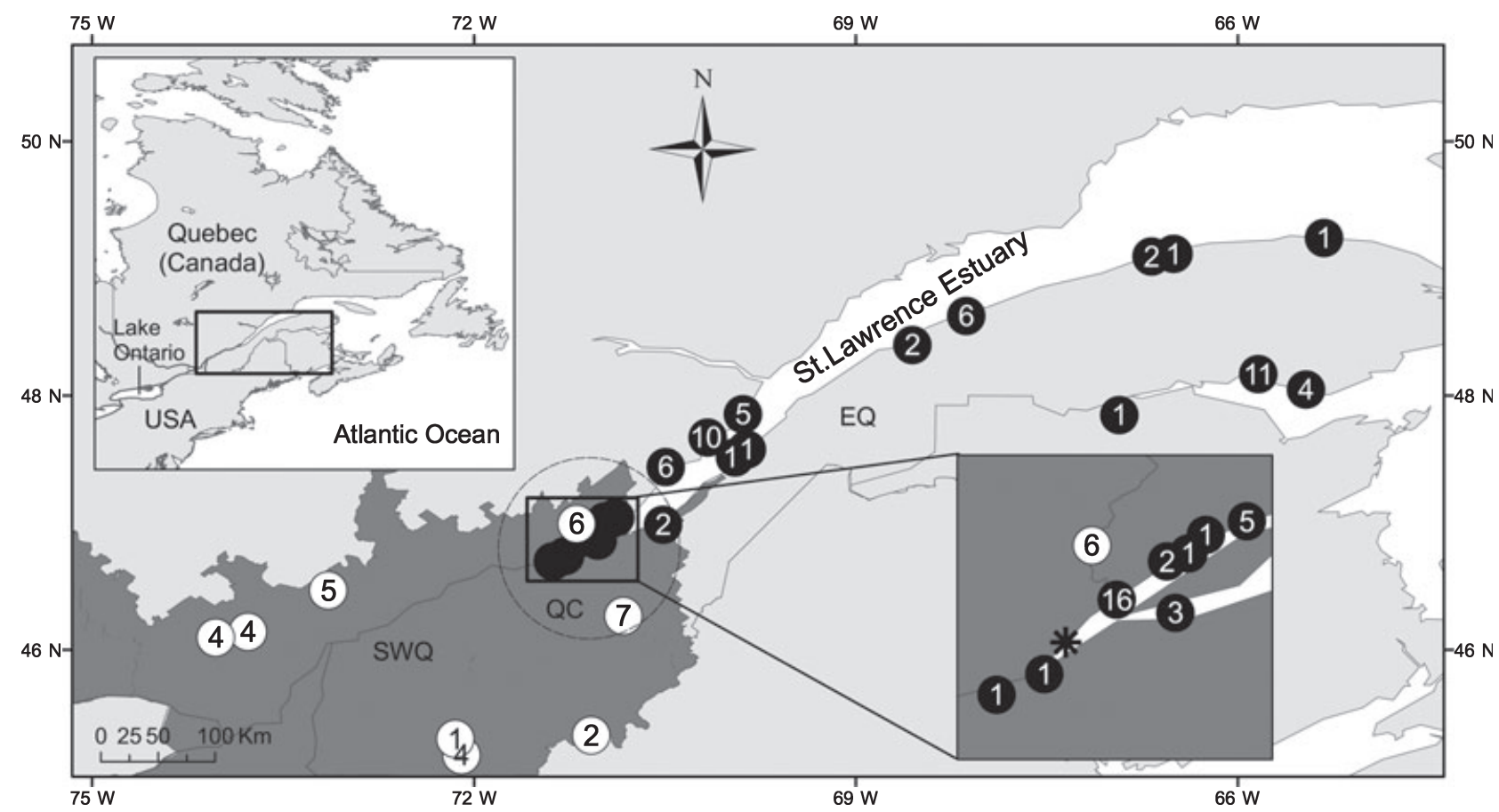

Fig. 1. Capture locations of the 116 rainbow trout (Oncorhynchus mykiss) analysed for otolith microchemistry (the eight fish from the Lacdes-Écorces hatchery are not presented). Numbers in the circles represent the sample sizes. Specimens $(N=33)$ used for determination of the threshold between freshwater and saltwater signatures are shown in white. The area where stocking and farming of rainbow trout is allowed is shown in dark grey. Quebec City is represented by an asterisk. SWQ: South-western Quebec region, QC: Quebec City region (encircled), and EQ: Eastern Quebec region. 


\section{Thibault et al.}

$1.517 \times 10^{-3}$. Mean $\mathrm{Sr}: \mathrm{Ca}+1$ SD was 0.790 $3.724 \times 10^{-3}$, with an average of $2.528 \times 10^{-3}$ (Fig. 2). More than $90 \%$ of all $\mathrm{Sr}: \mathrm{Ca}$ values were less than or equal to $3 \times 10^{-3}$. To be conservative, we decided to set the FW-threshold at $3.5 \times 10^{-3}$, which included $96 \%$ of the freshwater observations.

The phenotype of the 84 remaining rainbow trout (QC and EQ sectors) was determined by two methods. The first method consisted of visually interpreting the otolith $\mathrm{Sr}: \mathrm{Ca}$ transect of each individual from a point situated $100 \mu \mathrm{m}$ from the otolith's primordium to the otolith edge. Fish were classified as anadromous (A) or steelhead - if the two-point smoothed average curve exceeded the FW-threshold of $3.5 \times 10^{-3}$ anywhere along the otolith transect from $100 \mu \mathrm{m}$ outward. Fish were classified as freshwater resident rainbow trout (FW) when all values of the two-point smoothed average were less than the FW-threshold anywhere along the otolith transect from $100 \mu \mathrm{m}$ outward. Note that when only one point was located above or under the FW-threshold, it was not taken into account. At distances less than $100 \mu \mathrm{m}$ from the primordium, $\mathrm{Sr}$ :Ca values represented the maternal contribution (C. Donohoe, pers. comm., Institute of Marine Science, UCSC). If a gravid anadromous female does not stay in a freshwater spawning river for a long period before egg deposition, then a marine signal transmitted to the offspring otolith through the egg cytoplasm may be observed near the otolith core (Rieman et al. 1994; Volk et al. 2000; Zimmerman \& Reeves 2000, 2002; Donohoe et al. 2008). Fish exhibiting high Sr:Ca values between 0 and $100 \mu \mathrm{m}$ were therefore classified as the offspring of steelhead. Note that it was not possible to determine the maternal form for two rainbow trout because the $\mathrm{Sr}: \mathrm{Ca}$ transect did not begin at the otolith primordium.

Despite the fact that visual interpretation of $\mathrm{Sr}: \mathrm{Ca}$ patterns is common in studies using $\mathrm{Sr}: \mathrm{Ca}$ otolithom- etry (Tzeng et al. 2003; Gillanders 2005; Daverat et al. 2006; e.g., Tzeng et al. 2000; Zimmerman \& Reeves 2000), the method is quite subjective. More quantitative approaches have been recently proposed to avoid any reader bias (e.g.. Hedger et al. 2008). To validate results obtained with the conventional method, we also employed a quantitative approach based on nonparametric smoothing to interpret the otolith $\mathrm{Sr}: \mathrm{Ca}$ transects. Otolith sequences were smoothed using generalised additive models (GAMs). GAMs were used for modelling the relationship between $\mathrm{Sr}: \mathrm{Ca}$ ratio and distance from the otolith's primordium because there was no a priori reason to choose between the forms of the relationship. Use of GAMs enabled this relationship to be determined from the data (instead of being arbitrarily imposed). GAMs were fitted using the gam (mgcv) package of R (Wood 2006), using penalised regression splines. The degree of smoothness of the model term was estimated as part of fitting using generalised cross validation. GAMs were fitted separately to the maternal and offspring parts of the transect sequence. Determination of the transition from maternal to offspring parts of the sequence was based on the fact that the maternal signature could have been a mix of freshwater and saltwater $\mathrm{Sr}: \mathrm{Ca}$ ratios, but that the initial offspring signature must have been a freshwater $\mathrm{Sr}: \mathrm{Ca}$ ratio due to spawning in freshwater. The procedure for defining the break was as follows: (i) a distance of $100 \mu \mathrm{m}$ was defined as the initial break-point between maternal and offspring histories, (ii) an offspring GAM was fitted to all parts of the sequence at distances greater than the break-point (thus excluding the maternal history), (iii) if the part of the offspring GAM nearest to the primordium showed a saltwater signature (predicted values greater than the FW-threshold), then an extra $10 \mu \mathrm{m}$ was added to the break-point, (iv) steps $2-3$ were repeated until the part of the offspring GAM

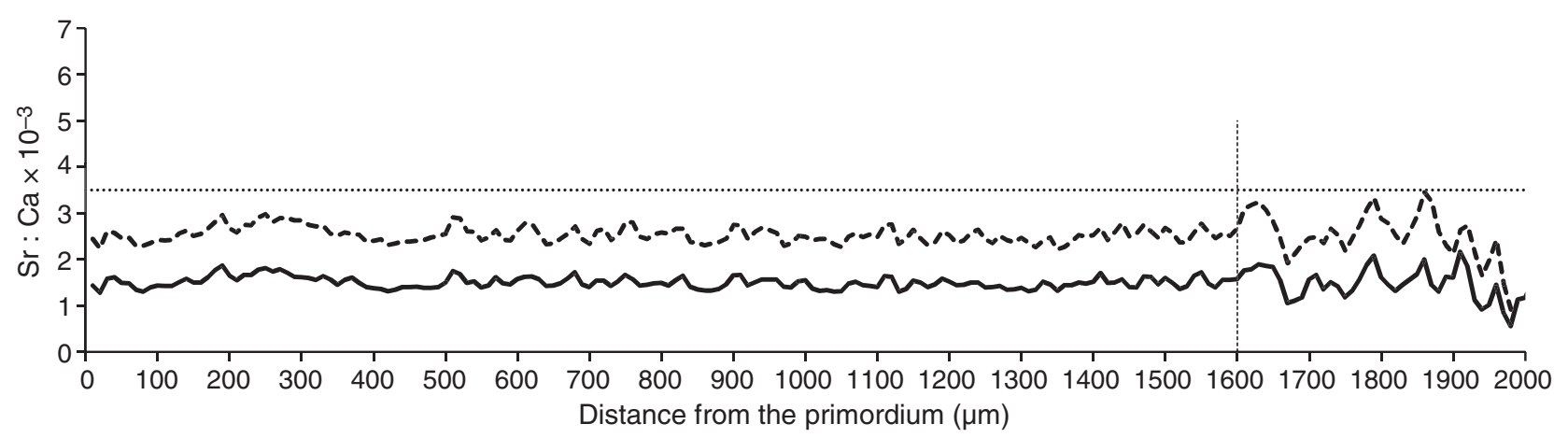

Fig. 2. Sr:Ca pattern (two-point smoothed averages) of 41 rainbow trout with a known freshwater residence phenotype. The full line corresponds to the mean Sr:Ca values, and the dashed line corresponds to the mean $+1 \mathrm{SD}$. The threshold of $3.5 \times 10^{-3}$, delineating freshwater and saltwater, is shown by a dotted horizontal line. The vertical line represents the distance from the otolith primordium beyond which the number of specimens is less than $30 \%$ of the sample. 
nearest to the core showed a freshwater signal, and (v) a maternal GAM was fitted to all parts of the sequence nearer to the primordium than the part of the sequence used to determine the offspring GAM. Otolith histories (maternal or offspring) were defined as being anadromous if any value predicted by the GAM exceeded the FW-threshold.

Comparing interpretations obtained with qualitative and quantitative methods, we found $92 \%$ and $87 \%$ of concordance for fish phenotypes and maternal forms respectively. Discordant interpretations $(N=18)$ consisted mainly (83\%) of anadromous categorisations according to the visual method as opposed to a freshwater residency classification obtained by the GAM method. Final categorisation followed the GAM's interpretation except in cases where obvious evidence (e.g., discordance between signal and capture location of the fish, abnormally low Sr:Ca values for an entire transect) supported the visual method result. Note that one fish classified as anadromous according to both methods was finally removed from the analysis as we suspected an edge effect (Jessop et al. 2002): it presented a sudden saltwater Sr:Ca signal at the very end of the otolith transect, despite being captured in freshwater.

\section{Life history of established versus invading rainbows}

Inside the stocking zone, where the majority of captured rainbow trout are believed to be cultured fish, all specimens should originate from a freshwater resident mother and present a freshwater residency phenotype. On the contrary, outside the boundaries of the stocking area, the FW-resident phenotype is expected only among established fish found in the two rivers where reproduction has been confirmed (i.e., Du Gouffre and Malbaie). All rainbows captured elsewhere, where the species is not believed to reproduce, were considered as vagrants. They thus should have experienced at least one marine phase representing the migration from their native stream to the river of capture using the St. Lawrence River ( $\geq 20$ PSU in this area, Lecomte \& Dodson 2004), a phase that should be reflected along the otolith transect by higher Sr:Ca values. Capture of putative vagrants with a solely freshwater signature would thus suggest that the species is reproducing in more rivers than documented to date. For both established fish and vagrants, the two maternal forms (resident or anadromous) are possible.

\section{Age and size at migration and growth rate}

Farmed strains are genetically selected to increase growth rates, and rearing conditions in hatcheries are designed to favour growth. Therefore, growth rates of farmed fish differ to those of fish originating from naturalised populations. Because fish found inside the stocking area limits probably originated in a hatchery, only fish from Eastern Quebec (Charlevoix, Bas-StLaurent and Gaspesia regions) were kept for size and growth analyses. The age of each remaining specimen $(N=51)$ was determined by two readers from otolith photographs (obtained after microprobe analyses and otoliths etched with $0.05 \mathrm{~N} \mathrm{HCl}$ ) by counting annuli. Given that the locations of the microprobe $\mathrm{Sr}: \mathrm{Ca}$ measurements were visible on the otolith photos, it was possible to identify the approximate position of each annulus on the $\mathrm{Sr}: \mathrm{Ca}$ transects, and therefore determine the age of fish at migration in the case of anadromous fish.

To estimate size at migration of steelhead, we backcalculated fish size to the age at habitat switch, as determined from otolith $\mathrm{Sr}$ :Ca ratios, according to the 'body proportional hypothesis' (BPH) technique (Francis 1990; Jessop et al. 2004; Brisson-Bonenfant 2006). The BPH equation is as follows:

$$
\log _{10} L_{i}=\left[\frac{\left(\mathrm{c}+d \log _{10} O_{i}\right)}{\left(\mathrm{c}+d \log _{10} O_{c}\right)}\right] \log _{10} L_{c}
$$

where $c$ is the intercept and $d$ is the slope of the body length-otolith radius (BL-OR) regression $\left(\log _{10} \mathrm{BL}=\right.$ $\left.1.33 \times \log _{10} \mathrm{OR}+2.35 ; N=93, R^{2}=0.82\right), L_{i}$ and $O_{i}$ are body length and otolith radius at age $i$, and $L_{c}$ and $O_{\text {c }}$ are body length and otolith radius at capture. Otolith radius and distances between annuli and the primordium were measured along the longest radius along the ventral side with image analysis software Image-Pro Express version 6.0 (Media Cybernetics Inc., Bethesda, MD, USA).

The size-at-age relationship was determined for both anadromous and resident fish in order to compare growth rates between life-history forms. Dates of capture varied among specimens, and current year growth was visible for some fish. To avoid bias, we back-calculated the size of each fish to their last visible annulus (i.e., to the spring preceding capture), instead of using size at capture.

\section{Results}

\section{General characteristics of sampled fish}

Specimens used for $\mathrm{Sr}: \mathrm{Ca}$ analyses (excluding fish from the LDE hatchery) showed a wide range of sizes and masses (Table 1). The overall sex ratio in our sample was 1.6, with a bias toward females. As expected, this bias was much more pronounced inside the stocking area (SWQ and QC) because when strains used for stocking are not triploid (and hence sterile), they often consisted of all-female lineages. Rainbow trout captured outside the stocking area, in Eastern Quebec (EQ), were all believed to be vagrants, except 


\section{Thibault et al.}

Table 1. Biological characteristics of 116 rainbow trout captured in Quebec's streams in 2005-2006 and used for otolith microchemistry analyses, including 33 specimens selected to determine the threshold between freshwater and saltwater signatures, but excluding the specimen eliminated because of otolith edge effect.

\begin{tabular}{|c|c|c|c|c|c|c|}
\hline \multirow[b]{2}{*}{ Sector of capture } & \multirow[b]{2}{*}{ Sex } & \multirow[b]{2}{*}{$N$} & \multicolumn{2}{|c|}{ Fork length (mm) } & \multicolumn{2}{|c|}{ Mass $\dagger(g)$} \\
\hline & & & Mean & Range & Mean & Range \\
\hline \multirow[t]{4}{*}{ South-western Quebec (SWQ) (inside stocking area) } & $\mathrm{F}$ & 10 & 321 & 229-406 & $513(9)$ & $294-1361$ \\
\hline & M & 3 & 274 & $250-323$ & $223(2)$ & $220-225$ \\
\hline & I & 1 & 229 & - & $?$ & - \\
\hline & $3 \mathrm{~N}$ & 6 & 287 & $210-559$ & 504 & $100-2381$ \\
\hline \multirow[t]{4}{*}{ Quebec City (QC) (inside stocking area) } & $\mathrm{F}$ & 17 & $245(16)$ & 119-495 & $89(10)$ & 20-291 \\
\hline & M & 7 & 179 & $124-260$ & 69 & $24-113$ \\
\hline & I & 5 & $229(3)$ & 229 & $135(3)$ & 135 \\
\hline & $3 \mathrm{~N}$ & 16 & $270(15)$ & $232-308$ & $174(11)$ & $113-340$ \\
\hline \multirow[t]{3}{*}{ Eastern Quebec (EQ) (outside stocking area) } & $\mathrm{F}$ & 24 & 343 & $176-334$ & $596(21)$ & $63-1364$ \\
\hline & M & 22 & 286 & $173-585$ & $325(20)$ & $54-1361$ \\
\hline & I & 5 & 235 & $90-317$ & $279(2)$ & $227-331$ \\
\hline
\end{tabular}

$\dagger$ Some fish were weighed after thawing.

Numbers in parentheses correspond to the $N$ used for calculating means when some data were missing.

F: female, M: male, I: sex not determined, 3N: triploid farmed fish

those coming from Du Gouffre and Malbaie Rivers, where natural reproduction is documented. In our sample, the oldest rainbow trout was 9-years old, whereas the youngest one was 1-year old (Table 2). On average, fish from the established population were older than those thought to be vagrants.

\section{Life history patterns: fish phenotype and maternal form}

Four main otolith $\mathrm{Sr}: \mathrm{Ca}$ life history patterns were observed: (i) FW-resident phenotype with a FW-resident maternal form (FW/FW, Fig. 3a, b), (ii) FW-resident phenotype with an anadromous maternal form (A/FW, Fig. 3c, d), (iii) anadromous phenotype with a FW-resident maternal form (FW/A, Fig. 3e, f), and (iv) anadromous phenotype with an anadromous maternal form (A/A, Fig. 3g, h). Fish sampled in the stocking area showed the same life history phenotype as their mother whereas this was not the case outside the stocking area in Eastern Quebec (Table 3). Among fish sampled in Eastern Quebec, 38\% of FW-residents originated from an anadromous mother, whereas $42 \%$ of anadromous trout originated from a FW-resident mother.

Occurrence of anadromy varied according to the capture location (Table 3 and Fig. 4). Inside the stocking area, that is, the Quebec City region, the

Table 2. Age of 51 rainbow trout found in Eastern Quebec (EQ), according to their region of capture.

\begin{tabular}{lrll}
\hline Region & $N$ & Mean & Range \\
\hline Charlevoix & & & \\
$\quad$ Du Gouffre and Malbaie $R$. & 16 & 5.5 & $4-9$ \\
$\quad 5$ ther & 5 & 2.8 & $2-3$ \\
Bas-St-Laurent & 10 & 3.3 & $1-7$ \\
Gaspesia & 20 & 3.5 & $3-6$ \\
\hline
\end{tabular}

FW-resident phenotype dominated the sample, and no specimen originated from a steelhead mother. In contrast, outside the stocking area (Eastern Quebec), the signal of anadromy, expressed either by the specimen's phenotype or the maternal form, dominated the sample. Based on a Chi-square analysis of the incidence of the saltwater signal as a function of distance from the stocking zone (Charlevoix, BasSt-Laurent, Gaspesia), the proportion of fish having experienced saltwater increased downstream $\left(\chi^{2}=\right.$ $8.87, N=51$, d.f. $=2, P=0.01)$. In the more upstream Charlevoix region, where natural reproduction is documented in two rivers, all specimens but one exhibited a FW-resident phenotype, but six (out of 20) appeared to be the offspring of anadromous mothers.

Most (74\%) of the rainbow trout showing either an anadromous phenotype or an anadromous maternal origin were captured in the regions bordering the downstream St. Lawrence Estuary (Bas-St-Laurent and Gaspesia). In these two regions, although we initially surmised no reproduction in these rivers and therefore expected only the anadromous phenotype, 18 rainbow trout showed a FW-resident life cycle, including two juveniles of 1- and 2-years old.

\section{Characteristics of the anadromous phenotype}

\section{Age at habitat change}

Thirteen rainbow trout, all found in Eastern Quebec (i.e., outside the stocking area), experienced at least one migration into saltwater. Characteristics of their life cycle are detailed in the Supporting Information. Briefly, most of them (62\%) migrated to the marine habitat at 3 years of age. Among the seven specimens that experienced at least one complete marine phase, three first migrated upstream at 4-years old, whereas it occurred one year later for a fourth individual. Three 
(a) 8

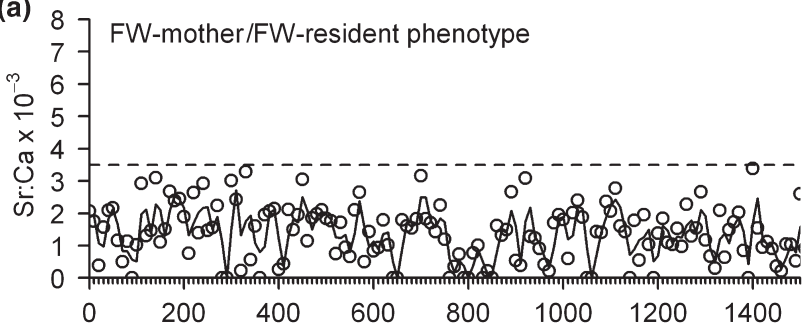

(c)

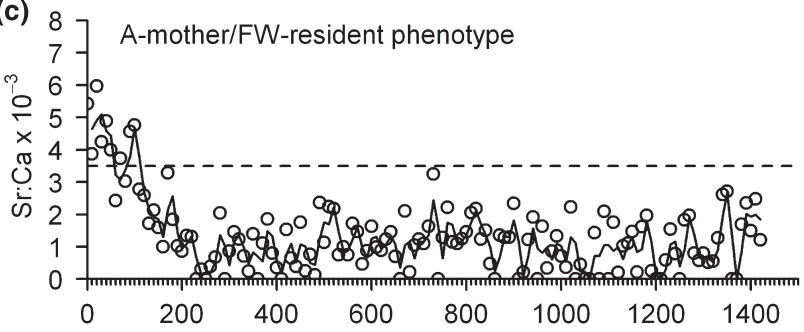

(e) 8

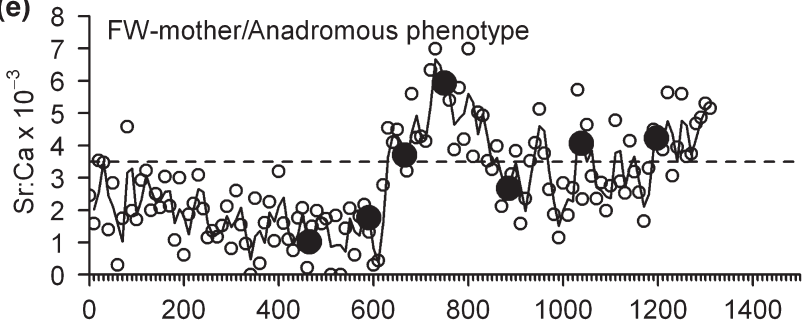

(g) 8

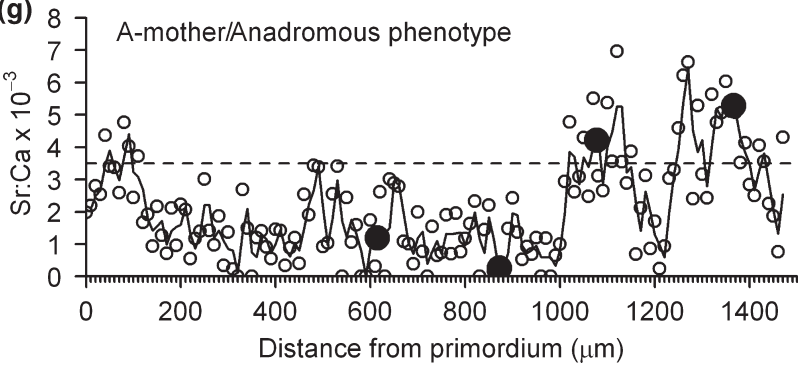

(b)

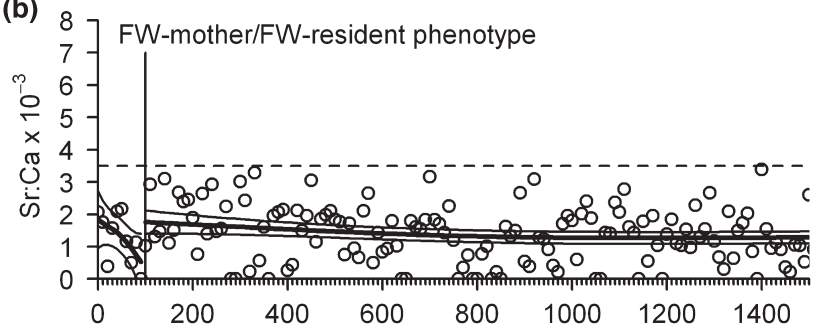

(d)
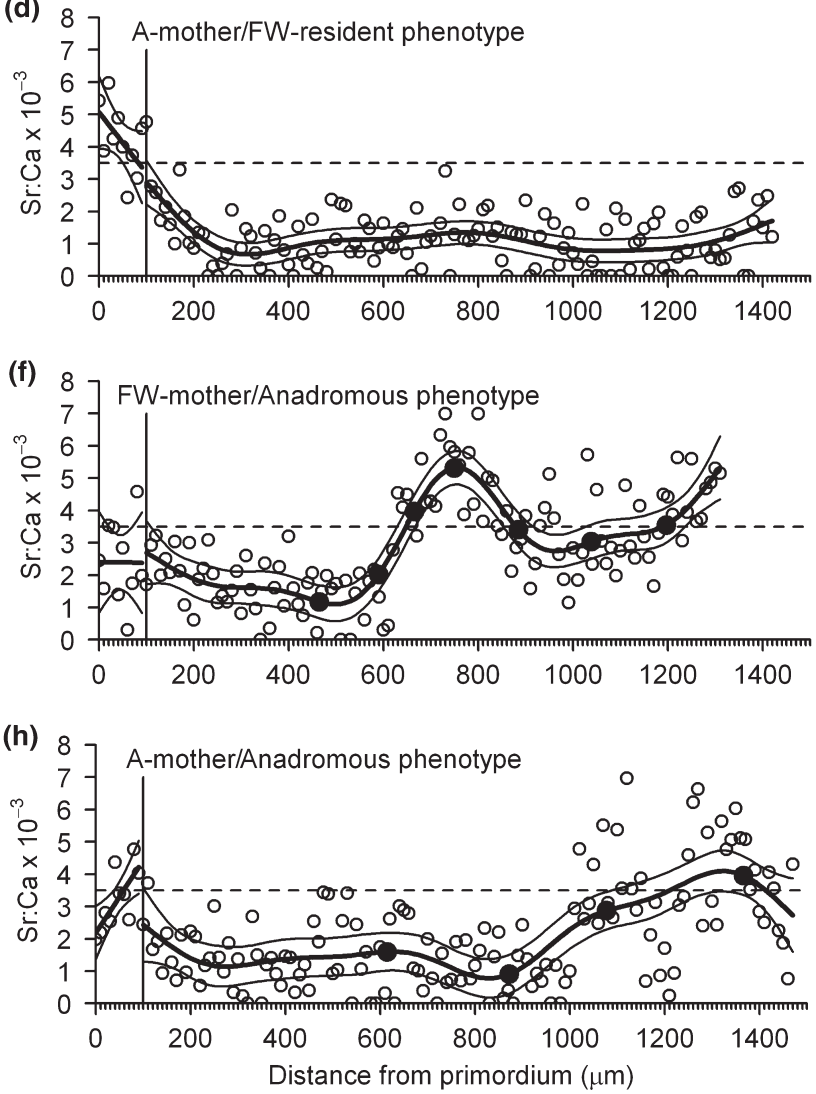

Fig. 3. Four otolith Sr:Ca life-history patterns observed in 83 rainbow trout (Oncorhynchus mykiss) captured in Eastern Quebec, as obtained by the visual interpretation method using the two-point smoothed averages (left panels), and the quantitative interpretation method using GAMs (right panels). Sr:Ca ratios between 0 and $\sim 100 \mu \mathrm{m}$ are associated with the maternal history, whereas Sr:Ca ratios between $100 \mu \mathrm{m}$ and the otolith edge represent the growing habitats experienced by the fish throughout its life time. Full circles represent the estimated position of each annulus. A-mother: anadromous maternal form, FW-mother: freshwater resident maternal form. The threshold of $3.5 \times 10^{-3}$, delineating between freshwater and saltwater, is shown by a dotted horizontal line.

specimens (female, male and unknown sex) were probably multispawners according to their age at change of habitat. All steelhead but two returned to freshwater during the growing season following the year of the seaward migration.

\section{Size at migration and growth rate}

Average fork length $( \pm \mathrm{SD})$ at the age of the first downstream migration (excluding the youngest migrant NO1, see supporting information) was $265 \pm 67 \mathrm{~mm}$ $(N=12$, range: $168-363 \mathrm{~mm})$. When fish first returned to freshwater, they measured $303 \pm 89 \mathrm{~mm}$ on average $(N=7$, range: $157-390 \mathrm{~mm})$. When removing younger specimens (NO1 and $\mathrm{PC} 2$ ) that might have been immature at that time, the mean fish length increased to $347 \pm 52 \mathrm{~mm}$ on average $(N=5$, range: 258 $390 \mathrm{~mm}$ ). Growth rate (length-at-age) observed for steelhead (excluding NO1) was the same as that for FWresidents [two-factor ANCOVA (age, form, age $\times$ form): d.f. $=36, F=28.74, P>0.05$, Fig. 5]. However, when size was back-calculated to the most common age for the first freshwater-to-sea migration, that is, at the age of 3 years, future steelhead tended to be larger than future FW-residents, but this difference was not significant $(268 \pm 61 \mathrm{~mm}$ vs. $252 \pm 73 \mathrm{~mm}$, Student's $t$-test: d.f. $=33, t$-value $=0.39, P=0.70)$. It must be 
Table 3. Life-history pattern of 83 rainbow trout captured in the Quebec City sector and in three different regions of Eastern Quebec (EQ), according to their sex. For two specimens, maternal form was not possible to determine.

\begin{tabular}{|c|c|c|c|c|c|c|c|c|}
\hline \multirow[b]{2}{*}{ Region } & \multirow[b]{2}{*}{ Sex } & \multicolumn{7}{|c|}{ Maternal form/Specimen's phenotype } \\
\hline & & $\mathrm{FW} / \mathrm{FW}$ & A/FW & FW/A & $A / A$ & ?/FW & $? / \mathrm{A}$ & N \\
\hline \multirow[t]{3}{*}{ Quebec City } & $F$ & 11 & 0 & 0 & 0 & 0 & 0 & 32 \\
\hline & M & 4 & 0 & 0 & 0 & 0 & 0 & \\
\hline & I & 17 & 0 & 0 & 0 & 0 & 0 & \\
\hline \multirow[t]{3}{*}{ Charlevoix (EQ) } & $F$ & 8 & 3 & 0 & 0 & 1 & 0 & 21 \\
\hline & M & 5 & 2 & 1 & 0 & 0 & 0 & \\
\hline & I & 0 & 1 & 0 & 0 & 0 & 0 & \\
\hline Bas-St- & $F$ & 2 & 2 & 2 & 1 & 0 & 0 & 10 \\
\hline \multirow[t]{2}{*}{ Laurent (EQ) } & M & 0 & 1 & 0 & 0 & 0 & 0 & \\
\hline & I & 2 & 0 & 0 & 0 & 0 & 0 & \\
\hline \multirow[t]{3}{*}{ Gaspesia (EQ) } & $F$ & 1 & 2 & 1 & 1 & 0 & 0 & 20 \\
\hline & M & 5 & 3 & 1 & 3 & 0 & 1 & \\
\hline & I & 0 & 0 & 0 & 2 & 0 & 0 & \\
\hline Total & - & 55 & 14 & 5 & 7 & 1 & 1 & 83 \\
\hline
\end{tabular}

FW, freshwater resident; A, anadromous; F, female; M, male; I, sex not determined (mainly triploid sterile fish).

noted however that all back-calculations were based on fish size in spring (at the time of annulus formation). Thus, estimation of size at migration does not take into account the fish's growth during summer, even if it changed habitat later during the growing season.

\section{Discussion}

Rainbow trout is slowly but surely invading Quebec streams, from the upper part of the St. Lawrence River where stocking is allowed, towards rivers located further downstream, outside the limits of the stocking area. The invasion process has led to the establishment of some self-sustaining populations in Eastern Québec, such as in two rivers of Charlevoix (Du Gouffre and Malbaie), where it forms a genetically distinct population (Thibault et al. 2009). As success of biological invasions usually depends on the presence of longdistance migrants (Begon et al. 1996), anadromy could have promoted the species' dispersion as steelhead can reach streams located far from their native river. Otolith microchemistry analysis performed on specimens captured inside and outside the stocking area revealed that although all fish in the Quebec City region were freshwater residents, both phenotypes (anadromous and freshwater resident) were found in Eastern Quebec. Moreover, the proportion of fish exhibiting the anadromous life cycle increased with the distance from the stocking zone.

\section{Anadromy in the newly established population of} Charlevoix

All rainbows captured in the Du Gouffre and Malbaie Rivers, where the species reproduces, exhibited a freshwater resident phenotype. However, $30 \%$ of them were produced by anadromous mothers, indicating the presence of an anadromous contingent in this population. The presence of anadromy (as revealed by the maternal form) increases the probability of population dispersal. Furthermore, our results support previous genetic analyses (Thibault et al. 2009) and contradict the belief that anadromy among introduced selfsustaining populations of rainbow trout only exists in the Santa Cruz River (Pascual et al. 2001; Riva Rossi et al. 2004). Moreover, our sampling in Du Gouffre and Malbaie Rivers was not representative of the real spatial and temporal distribution of the species. Specimens were caught during and after the reproduction period, mainly in the streams, and less so at the rivers' mouths. Therefore, capture of resident fish was more probable than anadromous fish that usually stay in the river only for the spawning period. Thus, the proportion of steelhead is probably underestimated. Predominance of freshwater resident rainbows in rivers supporting reproduction could also be related to sport fishing pressure. Rainbow trout has been fished in Du Gouffre and Malbaie Rivers for many years. Steelhead, being larger than residents, are targeted by fishers, so a decrease in the relative abundance of anadromous trout could be expected, as has been observed in a native population until the adoption of a catch-and-release policy (Kostow 2003).

\section{Anadromy and freshwater residency among vagrants}

As predicted, anadromy (revealed by fish phenotype and maternal forms) was predominant among vagrants captured in Bas-St-Laurent and Gaspesia regions, and was even probably slightly underestimated because of the capture of a few specimens too young to have undergone smoltification. The invasion process thus appears to be supported by long-distance migrants. However, the presence of freshwater residents was unexpected in these regions, as all the fish were believed to have migrated from populations established upstream in the St. Lawrence River system. The presence of nonmigratory fish in these rivers (especially in Gaspesia) and in the Noire River (next to the Malbaie R.), suggests that either there were illegal stocking events, or that the species is reproducing in these streams. Evidence suggests that punctual stockings have no influence on the rainbow trout colonisation process (Thibault et al. 2009). Thus the spread of established populations may be greater than previously indicated.

\section{Age and size at smoltification}

Most of the sampled steelhead exhibited a typical anadromous life cycle, with a first migration towards the marine habitat at approximately 3-years old and 

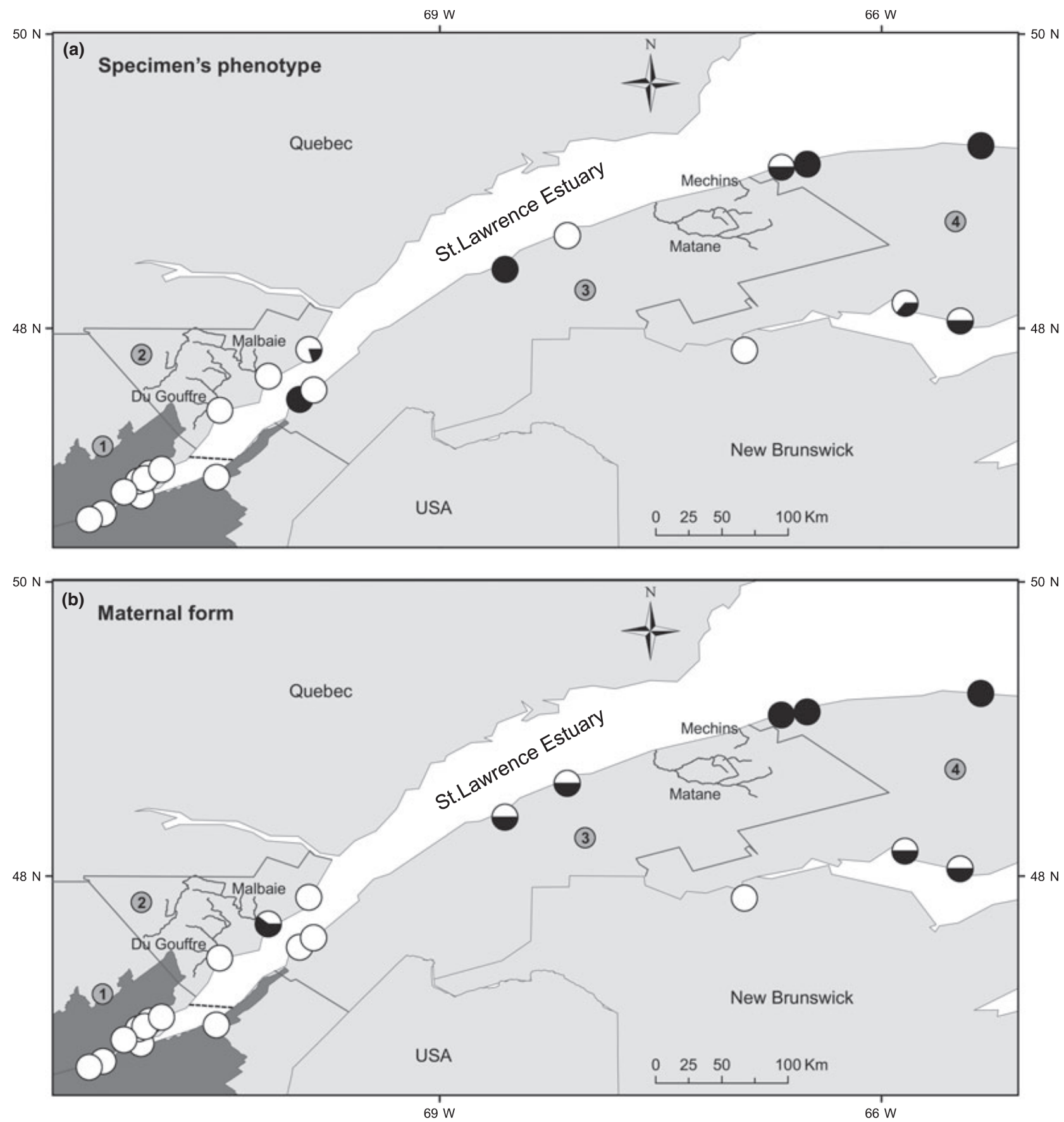

Fig. 4. Proportion of the anadromy and freshwater (FW)-residency forms in 83 rainbow trout (Oncorhynchus mykiss) captured in the Quebec City and Eastern Quebec regions, as determined from the otolith Sr:Ca patterns: (a) phenotype of analysed specimens, (b) maternal form. Anadromy is shown in black, whereas FW-residency is shown in white. Rivers where natural reproduction has been documented are labelled. The area where stocking and farming of rainbow trout is allowed is shown in dark grey. Approximate limit of the freshwater is indicated by a dashed line. 1: Quebec City region, 2: Charlevoix, 3: Bas-St-Laurent, and 4: Gaspesia.

measuring $\sim 265 \mathrm{~mm}$. The few younger migrants captured would constitute an exception (see below). The age at smoltification observed in Eastern Quebec is similar to that observed in juvenile steelhead within their native range where they usually spend 2 or 3 years in freshwater before migration (Burgner et al. 1992; Busby et al. 1996). However, Eastern Quebec steelhead appear to leave freshwater at a larger size than North American west coast steelhead (smolt size $\sim 160 \mathrm{~mm}$, Burgner et al. 1992). A great variation was found in size at migration, suggesting that migration is more related to age than to size. This contradicts general observations for $O$. mykiss and other salmonids indicating that smolt outmigration is related 


\section{Thibault et al.}

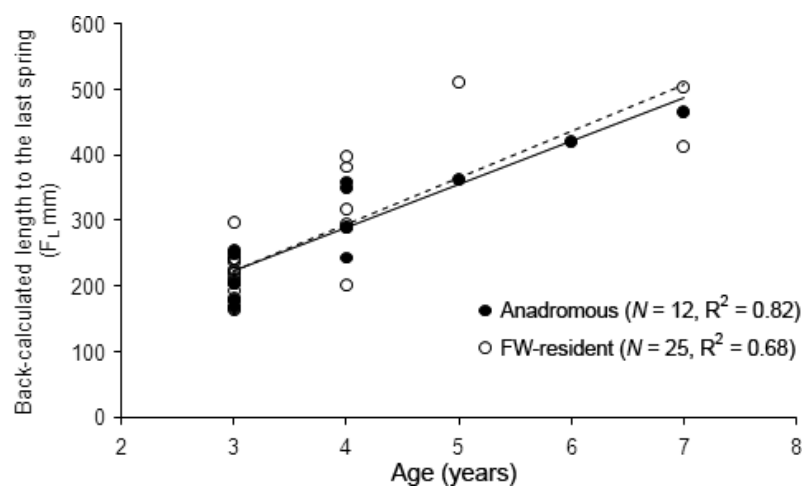

Fig. 5. Relationship between body length (fork length) and age for 37 anadromous and freshwater (FW)-resident rainbow trout (Oncorhynchus mykiss) captured in Eastern Quebec regions in 2005 and 2006.

to a critical size (Brisson-Bonenfant 2006 and references therein; Burgner et al. 1992). However, our results might be biased by small sample size and/or errors associated with the back-calculation method.

\section{Purpose of habitat changes}

All anadromous rainbow trout were found in rivers where no reproduction was expected. Therefore, we assumed that when they undertook their first seaward migration, they moved far away downstream of their native stream, never to return, and after a time spent in saltwater they finally entered into a new (non-native) river. The period spent in the marine habitat should not be considered only as a growing period before reproduction but also as an opportunity to move between rivers. We cannot be certain that migration into non-native rivers is solely for the purpose of reproduction. For example, a specimen captured in the Noire River (located approximately $30 \mathrm{~km}$ downstream of Malbaie River), that experienced precocious down- and upstream migrations, completed its marine phase before the age of two years (see Supporting Information). It appears unlikely that this fish was mature enough to reproduce. We rather suggest that it might have quickly migrated out of its native river (probably the Malbaie River), simply to switch rivers without necessarily spawning.

\section{Age at reproduction}

For almost all anadromous fish sampled in this study, the first return to freshwater occurred at 4 years of age. Despite the fact that the first upstream migration might not always be for the purpose of reproduction, it seems reasonable to affirm that the age at reproduction for most steelhead in Eastern Quebec is similar to steelhead within their native range, spawning at approximately 4-years old (range: 3-5) (Busby et al.
1996; Kostow 2003; Seamons et al. 2007). However, it should be noted that this conclusion is based on only a few individuals $(N=5)$ that had time to enter into the river for spawning before being captured.

\section{Multispawning of steelhead}

If repeat spawning is frequent among freshwater residents, then steelhead multispawners are believed to be generally few in populations of the temperate zone of the North American west coast, with an incidence usually (but not exclusively) less than 10\% (Burgner et al. 1992; Busby et al. 1996; Kostow 2003). In our study, three of the 13 fish exhibiting the anadromous life cycle were probably multispawners. Despite our small sample size, we think that the prevalence of multispawners in Eastern Quebec is probably higher than what has been reported in almost all coastal native populations (Narum et al. 2008a), but certainly less than what was observed in the naturalised population of the Santa Cruz River (60\%, Pascual et al. 2001). Multispawning can increase the success of invaders as this reproductive mode accelerates effective population growth and ensures genetic variability (Riva-Rossi et al. 2007; Narum et al. 2008a). This impact is enhanced when multispawners are anadromous females, which are known to be much more fecund than resident females (Kostow 2003).

\section{Determination of the phenotype}

Although we are unable to identify the life cycle of the fathers of our sampled fish, our results show that the maternal form is not necessarily expressed by its progeny. Within our sample in Eastern Quebec, we found resident rainbow trout with an anadromous maternal origin $(38 \%)$ and steelhead with a resident maternal origin (42\%). This is contrary to what was found by Zimmerman \& Reeves (2000) and Donohoe et al. (2008), using a similar approach. However, direct spawning observations, pedigree analyses and breeding experiments have previously demonstrated that both resident and anadromous parents can produce either freshwater resident or steelhead offspring (see references in Kostow 2003). Supporting these observations, population structure analyses conducted on sympatric resident and anadromous forms have shown a lack of strong genetic divergence between life-history forms (Pascual et al. 2001; Docker \& Heath 2003; Narum et al. 2004; Riva Rossi et al. 2004; Heath et al. 2008). Many environmental factors associated with a particular geographic area, such as habitat productivity, migratory hazards, habitat connectivity or freshwater mortality, have been proposed to explain the occurrence of the two life history strategies (Kostow 2003 and 
references therein; Narum et al. 2008b). However, as we found both forms in the same streams, it appears that the adoption of residency or anadromy is the expression of conditional, alternative developmental pathways under the control of threshold traits (Brockman \& Taborsky 2008).

We found no difference in growth rate (length-atage relationship) and size at the age of migration between anadromous and freshwater resident specimens. Based on previous studies on salmonids, we expected that future steelhead would be, just before migration, smaller than future residents (for a same age) (Thériault \& Dodson 2003 and references therein), but would thereafter experience a faster growth than freshwater residents (MacCrimmon \& Gots 1972; Thorpe 1994; Pascual et al. 2001). The absence of significant differences between the two life-history forms may have been related to purely methodological problems: (i) the number of anadromous specimens was low, (ii) sizes provided by fishers may have been incorrectly measured or (iii) annuli on otolith's pictures may have been wrongly positioned, or estimated distances between the otolith core and annuli may have been erroneous due to picture precision and unequal otolith grinding. Excluding growth, size-at-age and maternal form, other individual traits, such as sex or condition factor, could have played a role in the adoption of the phenotype. In this study, we found no relation between sex and a particular life history strategy, as the sex ratio was of 1:1 among anadromous fish. As the mass was not available for many specimen, it was not possible to investigate a potential role of condition factor in the adoption of a phenotype.

\section{Sampling bias and implications for extrapolation}

As the invasion process in still in progress and the number of rainbow trout in many rivers is low, our sampling effort was not systematic but was rather based on voluntary angler returns. As such, some caution is required in applying our conclusions to the situation as a whole. Nevertheless, the presence of consistent patterns within the different river categories (only freshwater residents in all rivers located upstream inside the stocking area (SWQ and QC), dominance of freshwater residents in established populations and dominance of anadromy in rivers of the Gaspesia and Bas-St-Laurent regions) indicates that our conclusions would probably apply in the case of increased sample sizes and locations. Nevertheless, future studies could focus the sampling efforts on a smaller number of rivers harbouring an abundance of rainbow trout and located at various distances from the established populations and stocking area to validate these preliminary conclusions.

\section{Concluding remarks}

As expected, otolith microchemistry analyses demonstrated that the invasion process by rainbow trout in Eastern Quebec is promoted by the presence of anadromous individuals that are able to colonise new rivers following long-distance migrations along the St. Lawrence Estuary corridor. In the newly established population of Charlevoix, anadromy was revealed by the maternal signature, indicating that the Santa Cruz River (Patagonia) is not the only introduced rainbow trout population that has developed an anadromous run. Surprisingly, some specimens with a freshwater resident phenotype were found among putative vagrants, suggesting the existence of unknown self-sustaining populations in Bas-St-Laurent and/or Gaspesia regions. These findings reveal the need for a more rigorous monitoring of the rivers in these regions, in order to monitor and mitigate the establishment of new rainbow trout populations in rivers supporting indigeneous salmonids such as Atlantic salmon (Salmo salar) and brook charr (Salvelinus fontinalis).

\section{Acknowledgements}

This work was funded by grants from the Natural Sciences and Engineering Research Council of Canada, Centre Interuniversitaire de Recherche sur le Saumon Atlantique (CIRSA), the Fédération Québécoise de la Faune and the Réseau Aquaculture de Québec. We thank our collaborators that helped to collect rainbow trout samples: Ministère des Ressources naturelles et de la faune, Québec Pêche, Fédération québécoise pour le saumon Atlantique, Fédération des gestionnaires de rivières à saumon du Québec, Simon Blanchet, and all ZECs, organisations, sport and commercial fishermen that participated in the sampling campaigns. A special thank to Véronique Thériault and Simon Blanchet for their implication in age determination. We are greatfull to Christopher Donohoe for his advice on the maternal $\mathrm{Sr}: \mathrm{Ca}$ signature interpretation, and to Rémy Pouliot for his comments on earlier versions of the manuscript.

\section{References}

Begon, M., Harper, J.L. \& Townsend, C.R. 1996. Ecology. Individuals populations and communities, 3rd edn. Blackwell Science, Cambridge, p. 1068.

Brisson-Bonenfant, C. 2006. Stratégie conditionnelle et migration chez le saumon atlantique (Salmo salar) juvénile. M.Sc. Thesis. Faculté des Sciences et de Génie, Département de biologie, Université Laval, Québec, 94 pp.

Brockman, H.J. \& Taborsky, M. 2008. Alternative reproductive tactics and the evolution of alternative allocation phenotypes. In: Oliveira, R.F., Taborsky, M. \& Brockman, H.J., eds. Alternative Reproductive tactics: an integrative approach. Cambridge University Press, Cambridge, pp. 25-51.

Burgner, R.L., Light, J.T., Margolis, L., Okazaki, T., Tautz, A. \& Ito, S. 1992. Distribution and origins of steelhead trout (Oncorhynchus mykiss) in offshore waters of the North 
Pacific ocean. International North Pacific Fisheries Commission, Bulletin 51: 73.

Busby, P.J., Wainwright, T.C., Bryant, G.J., Lierheimer, L.J., Waples, R.S., Waknitz, F.W. \& Lagomarsino, I.V. 1996. Status review of West Coast steelhead from Washington, Idaho, Oregon and California. NOAA Tech. Memo., NMFSNWFSC-27. US Dept. of Commerce, 261 pp.

Colautti, R.I., Grigorovich, I.A. \& MacIsaac, H.J. 2006. Propagule pressure: a null model for biological invasions. Biological Invasions 8: 1023-1037.

Daverat, F., Limburg, K.E., Thibault, I., Shiao, J.-C., Dodson, J.J., Caron, F., Tzeng, W.-N., Iizuka, Y. \& Wickström, H. 2006. Phenotypic plasticity of habitat use by three temperate eel species Anguilla anguilla, A. japonica and A. rostrata. Marine Ecology Progress Series 308: 231-241.

Docker, M.F. \& Heath, D.D. 2003. Genetic comparison between sympatric anadromous steelhead and freshwater resident rainbow trout in British Columbia, Canada. Conservation Genetics 4: 227-231.

Donohoe, C.J., Adams, P.B. \& Royer, C.F. 2008. Influence of water chemistry and migratory distance on ability to distinguish progeny of sympatric resident and anadromous rainbow trout (Oncorhynchus mykiss). Canadian Journal of Fisheries and Aquatic Sciences 65: 1160-1175.

DuBois, R.B., Plaster, S.D. \& Rasmussen, P.W. 1989. Fecundity of spring- and fall-run steelhead from two western Lake Superior tributaries. Transactions of the American Fisheries Society 118: 311-316.

Francis, R.I.C.C. 1990. Back-calculation of fish length: a critical review. Journal of Fish Biology 36: 883-902.

Gillanders, B.M. 2005. Otolith chemistry to determine movements of diadromous and freshwater fish. Aquatic Living Resources 18: 291-300.

GISD. 2005. Global Invasive Species Database. Oncorhynchus mykiss. Available from: http://www.issg.org/database/species/ ecology.asp? $\mathrm{si}=103 \& \mathrm{fr}=1 \&$ sts $=$ sss \&lang $=\mathrm{EN}$ (Accessed 26 th August 2009.

Gunn, J.S., Harrowfield, I.R., Proctor, C.H. \& Thresher, R.E. 1992. Electron microprobe analysis of fish otoliths - evaluation of techniques for studying age and stock discrimination. Journal of Experimental Marine Biology and Ecology 158: $1-36$.

Heath, D.D., Bettles, C.M., Jamieson, S., Stasiak, I. \& Docker, M.F. 2008. Genetic differentiation among sympatric migratory and resident life history forms of rainbow trout in British Columbia. Transactions of the American Fisheries Society 137: 1268-1277.

Hedger, R.D., Atkinson, P.M., Thibault, I. \& Dodson, J.J. 2008. A quantitative approach for classifying fish otolith strontium:calcium sequences into environmental histories. Ecological Informatics 3: 207-217.

Jessop, B.M., Shiao, J.-C., Iizuka, Y. \& Tzeng, W.N. 2002. Migratory behaviour and habitat use by American eels Anguilla rostrata as revealed by otolith microchemistry. Marine Ecology Progress Series 233: 217-229.

Jessop, B.M., Shiao, J.C., Iizuka, Y. \& Tzeng, W.N. 2004. Variation in the annual growth, by sex and migration history, of silver American eels Anguilla rostrata. Marine Ecology Progress Series 272: 231-244.

Jessop, B.M., Shiao, J.C., Iizuka, Y. \& Tzeng, W.N. 2008. Prevalence and intensity of occurrence of vaterite inclusions in aragonite otoliths of American eels Anguilla rostrata. Aquatic Biology 2: 171-178.

Kolar, C.S. \& Lodge, D.M. 2001. Progress in invasion biology: predicting invaders. Trends in Ecology and Evolution 16: 199-204.

Kostow, K. 2003. Factors that influence evolutionarily significant unit boundaries and status assessment in a highly polymorphic species, Oncorhynchus mykiss, in the Columbia Basin. Information Report \#2003-04. Oregon Department of Fish and Wildlife and NOAA Fisheries, $122 \mathrm{pp}$.

Lecomte, F. \& Dodson, J.J. 2004. Role of early life-history constraints and resource polymorphism in the segregation of sympatric populations of an estuarine fish. Evolutionary Ecology Research 6: 631-658.

MacCrimmon, H.R. 1971. World distribution of rainbow trout (Salmo gairdneri). Journal of Fisheries and Research Board of Canada 28: 663-704.

MacCrimmon, H.R. \& Gots, B.L. 1972. Rainbow trout in the Great Lakes. Ministry of Natural Resources, Ontario, 66 pp.

Moyle, P.B. \& Marchetti, M.P. 2006. Predicting invasion success: freshwater fishes in California as a model. BioScience 56: 515-524.

Narum, S.R., Contor, C., Talbot, A. \& Powell, M.S. 2004. Genetic divergence of sympatric resident and anadromous forms of Oncorhynchus mykiss in the Walla Walla River, U.S.A. Journal of Fish Biology 65: 471-488.

Narum, S.R., Hatch, D., Talbot, A.J., Moran, P. \& Powell, M.S. 2008a. Iteroparity in complex mating systems of steelhead Oncorhynchus mykiss (Walbaum). Journal of Fish Biology 72: 45-60.

Narum, S.R., Zendt, J.S., Graves, D. \& Sharp, W.R. 2008b. Influence of landscape on resident and anadromous life history types of Oncorhynchus mykiss. Canadian Journal of Fisheries and Aquatic Sciences 65: 1013-1023.

Pascual, M.A., Bentzen, P., Riva-Rossi, C.M., Mackey, G., Kinnison, M.T. \& Walker, R. 2001. First documented case of anadromy in a population of introduced rainbow trout in Patagonia, Argentina. Transactions of the American Fisheries Society 130: 53-67.

Reed, S.J.B. 1993. Electron microprobe analysis, 2nd edn. Cambridge University Press, Cambridge, 326 pp.

Rieman, B.E., Myers, D.L. \& Nielsen, R.L. 1994. Use of otolith microchemistry to discriminate Oncorhynchus nerka of resident and anadromous origin. Canadian Journal of Fisheries and Aquatic Sciences 51: 68-77.

Riva Rossi, C.M., Lessa, E.P. \& Pascual, M.A. 2004. The origin of introduced rainbow trout (Oncorhynchus mykiss) in the Santa Cruz River, Patagonia, Argentina, as inferred from mitochondrial DNA. Canadian Journal of Fisheries and Aquatic Sciences 61: 1095-1101.

Riva-Rossi, C., Pascual, M.A., Babaluk, J.A., García-Asorey, M. \& Halden, N.M. 2007. Intra-population variation in anadromy and reproductive life span in rainbow trout introduced in the Santa Cruz River, Argentina. Journal of Fish Biology 70: 1780-1797.

Seamons, T.R., Bentzen, P. \& Quinn, T.P. 2007. DNA parentage analysis reveals inter-annual variation in selection: results from 19 consecutive brood years in steelhead trout. Evolutionary Ecology Research 9: 409-431.

Theoharides, K.A. \& Dukes, J.S. 2007. Plant invasion across space and time: factors affecting nonindigenous species 
success during four stages of invasion. New Phytologist 176: 256-273.

Thériault, V. \& Dodson, J.J. 2003. Body size and the adoption of a migratory tactic in brook charr. Journal of Fish Biology 63: 1144-1159.

Thibault, I., Bernatchez, L. \& Dodson, J.J. 2009. The contribution of newly-established populations to the dynamics of range expansion in a one-dimensional fluvial-estuarine system: the case of rainbow trout (Oncorhynchus mykiss) in Eastern Quebec. Diversity and Distributions 15: 1060-1072.

Thorpe, J.E. 1994. Salmonid fishes and the estuarine environment. Estuaries 17: 76-93.

Tzeng, W.-N., Wang, C.H., Wickström, H. \& Reizenstein, M. 2000. Occurence of the semi-catadromous European eel Anguilla anguilla in the Baltic Sea. Marine Biology 137: 93-98.

Tzeng, W.-N., Iizuka, Y., Shiao, J.C., Yamada, Y. \& Oka, H.P. 2003. Identification and growth rates comparison of divergent migratory contingents of Japanese eel (Anguilla anguilla). Aquaculture 216: 77-86.

Tzeng, W.-N., Chang, C.-W., Wang, C.-H., Shiao, J.-C., Iizuka, Y., Yang, Y.-J., You, C.-F. \& Lozys, L. 2007. Misidentification of the migratory history of anguillid eels by $\mathrm{Sr} / \mathrm{Ca}$ ratios of vaterite otoliths. Marine and Freshwater Research 348: 285-295.

Volk, E.C., Blakley, A., Schroder, S.L. \& Kuehner, S.M. 2000. Otolith chemistry reflects migratory characteristics of Pacific salmonids: Using otolith core chemistry to distinguish maternal associations with sea and freshwaters. Fisheries Research 46: 251-266.

Wood, S.N. 2006. Generalized additive models: an introduction with R. Chapman and Hall/CRC, Boca Raton, FL, 416 pp.
Zimmerman, C.E. 2005. Relationship of otolith strontium-tocalcium ratios and salinity: experimental validation for juvenile salmonids. Canadian Journal of Fisheries and Aquatic Sciences 62: 88-97.

Zimmerman, C.E. \& Reeves, G.H. 2000. Population structure of sympatric anadromous and nonanadromous Oncorhynchus mykiss: evidence from spawning surveys and otolith microchemistry. Canadian Journal of Fisheries and Aquatic Sciences 57: 2152-2162.

Zimmerman, C.E. \& Reeves, G.H. 2002. Identification of steelhead and resident rainbow trout progeny in the Deschutes River, Oregon, revealed with otolith microchemistry. Transactions of the American Fisheries Society 131: 986-993.

\section{Supporting Information}

Additional Supporting Information may be found in the online version of this article:

Appendix A. Age at migration for 13 anadromous rainbow trout captured in 2006 in Eastern Quebec regions, as revealed by otolith microchemistry. "+" refers to fish age during the growing season (late spring to early fall), "++" refers to fish age at fall, absence of "+" refers to fish age at early spring

Please note: Wiley-Blackwell are not responsible for the content or functionality of any supporting materials supplied by the authors. Any queries (other than missing material) should be directed to the corresponding author for the article. 